\title{
Investigating the roles of meteorological factors in COVID-19 transmission in Northern Italy
}

\author{
Ambreen Khursheed $^{1}$ (D) Faisal Mustafa ${ }^{1,2} \cdot$ Ayesha Akhtar $^{1,2}$ \\ Received: 17 April 2020 / Accepted: 16 April 2021 / Published online: 28 April 2021 \\ (C) The Author(s), under exclusive licence to Springer-Verlag GmbH Germany, part of Springer Nature 2021
}

\begin{abstract}
The novel COVID-19 is a highly invasive, pathogenic, and transmittable disease that has stressed the health care sector and hampered global development. Information of other viral respiratory diseases indicates that COVID-19 transmission could be affected by varying weather conditions; however, the impact of meteorological factors on the COVID-19 death counts remains unexplored. By investigating the impact of meteorological factors (absolute humidity, relative humidity, and temperature), this study will contribute both theoretically and practically to the concerned domain of pandemic management to be better prepared to control the spread of the disease. For this study, data is collected from 23 February to 31 March 2020 for Milan, Northern Italy, one of the badly hit regions by COVID-19. The generalized additive model (GAM) is applied, and a nonlinear relationship is examined with penalized spline methods. A sensitivity analysis is conducted for the verification of model results. The results reveal that temperature, relative humidity, and absolute humidity have a significant but negative relationship with the COVID-19 mortality rate. Therefore, it is possible to postulate that cool and dry environmental conditions promote virus transmission, leading to an increase in COVID-19 death counts. The results may facilitate health care policymakers in developing and implementing effective control measures in a timely and efficient way.
\end{abstract}

Keywords COVID-19 $\cdot$ Temperature $\cdot$ Generalized additive model $\cdot$ Humidity $\cdot$ Air quality

\section{Introduction}

The emergence of the 2019 novel coronavirus infection was observed in Wuhan, a renowned city of China, when the first infected case of this virus appeared in December 2019 (Lu et al. 2020). The prevalence of coronavirus reached its peak at the start of the new year 2020. Initially, the new coronavirus was restricted to China, but soon, it affected many other countries ( $\mathrm{Li}$ et al. 2020; Wang et al. 2020a, b, c; Mustafa et al. 2021). As per global

Responsible Editor: Philippe Garrigues

Ambreen Khursheed

ambreen.khursheed@ucp.edu.pk

Faisal Mustafa

faisal.mustafa@ucp.edu.pk

Ayesha Akhtar

ayeshaakhtar@ucp.edu.pk

1 UCP Business School, University of Central Punjab, Lahore, Pakistan

2 University of Central Punjab, Lahore, Pakistan statistics, $2019 \mathrm{nCoV}$ infected more than 43,000 persons in 28 different countries of the world. This harrowing statistic alarmed the world that $2019 \mathrm{nCoV}$ was a major global health concern. The World Health Organization (WHO) made an important official announcement on 11 February 2020, in which the 2019 $\mathrm{nCoV}$ pandemic disease was titled with a new name as coronavirus disease (COVID-19). Keeping in mind the nature of COVID-19, the International Committee on Taxonomy of Viruses gave another name to the 2019 novel coronavirus as severe acute respiratory syndrome coronavirus-2 (SARS-CoV-2) (Gorbalenya et al. 2020).

Although primary analysis established a connection between the wild animal market and infected patients, pointing towards the existence of animal-to-human transference (Gralinski and Menachery 2020), nevertheless, the most recent studies examined that droplets or direct contact with people caused the human-tohuman transference of SARS-CoV-2 (Li et al. 2020; Wang et al. 2020a, b, c; Carlos et al. 2020). However, as the situation is getting worse, therefore, it is significant to determine the factors leading to COVID-19 spread. Additionally, WHO also emphasized that more research is still required to advance public health measures and prediction models (Smit et al. 2020). 
Among other factors, prior studies have highlighted the crucial role of weather conditions regarding the spread of viral diseases. Additionally, epidemiological models have been applied to formulate regulatory intervention and policy imposition (Tanne et al. 2020; Cai et al. 2020). Several studies were conducted to explore reasons behind the spread of viral diseases and to develop control strategies by determining the influence of meteorological factors on outbreaks such as dengue fever (Morin et al. 2013), varicella (Mahmud et al. 2020), and influenza (Liu et al. 2020a, 2020b). Past studies have documented that among meteorological factors, humidity and temperature in particular have a significant impact on the spread of COVID-19 (Bashir et al. 2020; Iqbal et al. 2020). Recently, some studies explored a significant relationship between weather conditions and COVID-19 transmission and mortality rate (Wang et al. 2020a, b, c; Oliveiros et al. 2020). Many researchers claimed temperature and humidity as crucial contributors in predicting the COVID-19 transmission (Kodera et al. 2020; Ma et al. 2020; Biktasheva 2020; Wu et al. 2020).

Given the similarities between COVID-19 and SARS virus, researchers hypothesized that the transmission rate of the COVID-19 may be partially decreased when temperature and humidity increase (Wu et al. 2020; Pan et al. 2021). Likewise, as per a recent study, it was found that COVID-19 infection and death rates are high in cold weather, that is, about $50 \%$ of the cases have a seasonal effect (Liuab et al. 2021). Moreover, Ficetola and Rubolini (2020) reported that the COVID-19 transmission reaches its peak at a temperature range of $5-6.3^{\circ} \mathrm{C}$. While the required humidity level for its peak transmission is reported as $\sim 4-6 \mathrm{~g} \cdot \mathrm{m}^{-3}$. The seminal work of Leung et al. (2020) supported the argument by documenting that lower humidity and temperature are highly expected to promote COVID19 spread. Similarly, Lin et al. (2020) revealed that rising levels of temperature directly contribute to mitigating the transmission of COVID-19. Thus, recent studies have strengthened the hypothesized relationship between COVID-19 and meteorological factors (Smit et al. 2020; Ma et al. 2020).

Studies conducted in different parts of the world have determined the weather effects on COVID-19 transmission rate, but none attempted to determine the impact of meteorological factors (absolute humidity, relative humidity, and temperature) on the COVID-19 mortality rate, particularly in the context of Milan, Northern Italy. Therefore, it is imperative to investigate all the possible factors, especially environment related, that either directly or indirectly lead to COVID-19 or increase the graph of the death rate.

The northern region of Italy consists of eight separate regions: Trentino-Alto, Liguria, Peidmont, Veneto, Aosta Valley, FriuliVenezia Giulia, Emilia-Romagna, and Lombardy. The population of Northern Italy is approximately 27.2 million. Among these regions, Lombardy is the home to 10.08 million inhabitants, and it reported $37 \%$ of COVID-19 cases and $53 \%$ deaths by 15 April 2020 (Rate, 2020). Italy adopted different strategies for controlling this pandemic, including mass testing and strict repression of the outbreak implemented by Veneto. While Lombardy improved hospital services to meet the growing demand for intensive care units; however, it reported three times higher COVID-19 death cases (18.3\%) as compared to Veneto $(6.4 \%)$ and approximately two times higher than the rest of Italy (10\%) as reported on April 15 (Boccia et al. 2020; Signorelli et al. 2020). In Lombardy, the city of Milan reported a huge number of COVID-19 death cases (Silvia 2020). Hence, this situation highlighted a research gap to explore the meteorological factors causing the highest number of COVID-19 mortality cases in Milan. Additionally, this situation also highlights the significance of critically assessing factors of environmental sensitivity in the coronavirus because before developing any response strategy, it is important to understand how meteorological factors can influence the COVID-19 pandemic. Moreover, COVID-19 spreads through close contact and respiratory droplets; it is noteworthy to expand the roots of the research for the study of the unexplored combination of variables that would help to better understand the dynamics of this deadly virus and assist knowledge workers to come up with effective countermeasures.

The study contributes to the existing literature in the following ways. First, this study aims to help health care practitioners in understanding the role of temperature and humidity in understanding the COVID-19 death counts and to provide a reliable prediction of the linkages between humidity and temperature and COVID-19 mortality. This information will provide a basis for developing effective policies and measures to minimize the transmission rate of COVID-19. Second, several studies provided significant findings proving the relationship between meteorological factors and the COVID-19 mortality rate (Pinheiro et al. 2014; Wang et al. 2020; Oliveiros et al. 2020). However, no study has determined the relationship between Milan's weather conditions and COVID-19 death cases, particularly during its peak period. Thus, the aim of this research is to give scientific evidence about the impact of weather conditions on the COVID19 death cases in Milan, Italy. Third, this research aims to reveal that in addition to the indoor transmission of COVID-19, outdoor airborne virus transmission might be a major pathway in COVID-19 transmission. Fourth, this study adds distinction in its analytical methodology by applying a robust approach: generalized additive model (GAM) with quasi-Poisson link function on the data of Milan, Italy.

\section{Methodology}

\section{Data collection}

Climate conditions are reported as one of the top predictors of COVID-19 infections (Ma et al. 2020). In this study, exploring the relationship between COVID-19 and death cases, we collected the data for Milan, a city in the northern region of 
Italy. The reason for selecting this particular region is the highest number of reported COVID-19 death cases during the selected peak period from 23 February to 31 March 2020. We used meteorological variables composed of absolute humidity, relative humidity, and daily average temperature. Time series meteorological data of daily average humidity $(\mathrm{H})$ and daily average temperature $(\mathrm{T})$ for Milan were collected from Weather Underground (https://www. wunderground.com/).

While the data of air pollutants composed of particulate matter with sulfur dioxide $\left(\mathrm{SO}_{2}\right)$, nitrogen dioxide $\left(\mathrm{NO}_{2}\right)$, aerodynamic diameter $\leq 2.5 \mu \mathrm{m}\left(\mathrm{PM}_{2.5}\right)$, ozone $\left(\mathrm{O}_{3}\right)$, aerodynamic diameter $\leq 10 \mu \mathrm{m}\left(\mathrm{PM}_{10}\right)$, carbon monoxide $(\mathrm{CO})$, and ammonia $\left(\mathrm{NH}_{3}\right)$ were collected from the official website of World Air Quality Index (AQI) (https://aqicn.org/city/italy/ lombardia/milano-pascal-citta-studi/). Recent studies have confirmed the authenticity of selected websites for the data collection for examining meteorological factors (Zoran et al. 2020; Pani et al. 2020; Lolli et al. 2020). The real-time data for COVID-19 death cases were collected from Statista's website (https://www.statista.com/statistics/1109295/provinces-withmost-coronavirus-cases-in-italy/) (Rasmussen and Jamieson 2020). This study attempts to investigate the nonlinear relationship between COVID-19 death cases and meteorological factors in Milan, Italy. We expect that this research can contribute to the existing literature by providing scientific evidence for implementing effective control measures in COVID-19.

\section{Absolute humidity calculation}

In an atmosphere, the amount of water vapors is variable and small. Absolute humidity is assessed through vapor pressure (VP). The absolute humidity is the mass of moisture per volume of air $\left[\mathrm{p} v\left(\mathrm{~g} / \mathrm{m}^{3}\right)\right]$. It is linked to vapor pressure through the ideal gas law for the moist air portion. Following the model provided by $\mathrm{Ma}$ et al. (2020), this study develops and presents Eq. (1), in which $G_{\mathrm{s}}$ is the gas constant for water vapor; $v$ represents vapor pressure $(\mathrm{VP}),[461.53 \mathrm{~J} /(\mathrm{kg} \mathrm{K})]$; and $\mathrm{T}$ represents daily ambient temperature $(\mathrm{K})$.

$\rho v=1000 \times v / \mathrm{G}_{\mathrm{s}} \mathrm{T}$

Absolute humidity is normally represented by VP and is examined through relative humidity and ambient temperature by applying Clausius-Clapeyron relation (O'Gorman and Muller 2010; Ma et al. 2020). Initially, we calculated saturated vapor pressure $\left[\mathrm{S}_{\mathrm{a}}(\mathrm{T})(\mathrm{mb})\right]$ by using daily temperature as shown in the equation below:

$\mathrm{S}_{\mathrm{a}}(\mathrm{T})=\mathrm{S}_{\mathrm{a}}\left(\mathrm{T}_{\mathrm{o}}\right) \times \exp \left[\mathrm{L} / \mathrm{Gs}\left(1 / \mathrm{T}_{\mathrm{o}}-1 / \mathrm{T}\right)\right]$
$\mathrm{VP}=1000 \times \mathrm{Gs}(T) \times \mathrm{RH} / 1000$

where the saturation vapor pressure is represented by $S_{a}$ $\left(\mathrm{T}_{\mathrm{o}}\right)$ and the reference temperature is $\mathrm{T}_{\mathrm{o}}(273.15 \mathrm{~K})$, which is equivalent to $6.11 \mathrm{mb}$. Gs represents $[461.53 \mathrm{~J} /(\mathrm{kg} \mathrm{K})]$ the value of gas constant for water vapor. L represents the standard latent heat required for evaporating $1 \mathrm{~kg}$ of water and that is $2257 \mathrm{~kJ} / \mathrm{kg}$. T shows daily ambient temperature $(\mathrm{K})$. In this study, we used absolute humidity, relative humidity, and temperature for investigating its impact on reported death cases in Milan, Northern Italy. We calculated the value of VP by combining the relative humidity (RH) with $\mathrm{S}_{\mathrm{a}}$ from Eq. (2).

\section{Statistical methods}

The data is examined with the help of descriptive statistics and a generalized additive model (GAM). In this study, we have proposed that a nonlinear relationship exists between meteorological factors and COVID-19 death cases. The reason is because a real relationship between COVID-19 and meteorological factors is complex and is not necessarily linear (Luo et al. 2021). Therefore, in order to investigate the spatial variation in the linkage between COVID-19 death cases and meteorological factors, it is imperative to investigate the nonlinear relationship. Past studies have also stated that COVID-19 and meteorological factors are more likely to exhibit a nonlinear relationship rather than a linear relationship (Chien and Chen 2020; Xie and Zhu 2020). Further, researchers also applied lagged impact of temperature (Anderson and Bell 2009; Teklehaimanot et al. 2004) because of the presence of lag effect along with the nonlinearity regarding the relationship among air quality, temperature, and the number of death cases or diseases (Yang et al. 2012; Wu et al. 2013; Breitner et al. 2014; Fischer et al. 2015). Data were analyzed through the semiparametric generalized additive model (GAM) approach. GAM is derived from a generalized linear model (GLM) as in GAM-independent variables can be modeled nonparametrically besides polynomial and linear terms. We selected this approach because many existing research studies reported this model could effectively provide lesser biases in comparison to other methods such as the quasi partial autocorrelation functions (PACF) of residuals or Akaike information criteria (AIC) (Wang et al. 2020a, b, c; Ahmad et al. 2018; Zhu et al. 2020). Further, we want to test a complex relationship in this study, and GAM is one of the most suitable methods to test highly complex nonlinear relationships along with a huge number of complex potential predictors. Past studies highlighted the significance of using robust statistical methods in empirical studies (Mustafa et al. 2018; Nasir et al. 2020; Khursheed et al. 2020a, 2020b). Therefore, we applied GAM with a quasi-Poisson link function based on its significance in testing highly complicated relationships (Chen et al. 2017a, 2017b; Ravindra et al. 2019). Moreover, several 
studies on COVID-19 and meteorological factors have also applied GAM for testing the relationship, such as Prata et al. (2020), using the generalized additive model (GAM) to determine the relationship between COVID-19 cases and temperature in Brazil. Likewise, Qi et al. (2020), Liu et al. (2020a, b), and Zhu et al. (2020) also applied the GAM method to explore the relationship between COVID-19 cases and meteorological factors in China. Further, Ma et al. (2020) applied the GAM method to determine the impact of temperature and humidity changes on the COVID-19 death counts in Wuhan, China. Therefore, GAM is the most suitable approach to determine the impact of nonlinear weather effects on health (Xie and Zhu 2020). Thus, we applied a semiparametric generalized additive model (GAM) for investigating the relationship between meteorological factors and COVID-19 daily death counts in Milan, Northern Italy.

The basic models for a total number of reported death cases excluding the effect of air pollution variables are developed. For having an adjustable model, we used smoothed time functions, which considered a nonlinear relationship between death cases and time. After this, we added meteorological factors and examined their impact on COVID-19 death cases. For examining the model fitness, we used the Akaike information criterion (AIC) (Bozdogan 1987). In consideration of past research studies on time series data, we used penalized smoothing spline function for controlling the effects of confounding factors, for instance, time trends and day and air pollution data (Luo et al 1998; Araveeporn 2019). The core GAM equation is as follows:

$$
\begin{aligned}
& \log \mathrm{E}\left(\mathrm{y}_{\mathrm{d}}\right)=\alpha+\beta \mathrm{W}_{\mathrm{d}}+\mathrm{NS} \\
& \quad(\text { air contamination, } \mathrm{k}=\mathrm{df}+1)+\mathrm{NS}(\text { Time, } \mathrm{K}=\mathrm{DF}+1)+\mathrm{WD}
\end{aligned}
$$

In Eq. (4), d represents the day of observation. E( $\left.\mathrm{Y}_{\mathrm{d}}\right)$ shows the anticipated number of death cases due to COVID-19 on the day, $\alpha$ represents the intercept, $\beta$ shows regression coefficient, and $\mathrm{W}_{\mathrm{d}}$ represents weather variable on daily basis on the day (d). $W_{d}$ is taken as a categorical variable for denoting weekday. NS shows the smoother based on penalized smoothing spline function. For analyzing time trends following AIC, 2 degrees of freedom $(d f)$ is considered (Gasparrini et al. 2010). While $3 d f$ is considered for analyzing absolute humidity, relative humidity, and temperature. Then we examined the lag effects of weather situation on the number of COVID-19 casualties. We have set lags at equally spaced values on the $\log$ scale. For exploring the effect of temperature, absolute humidity, and relative humidity over different lag days in Milan, Italy, we assessed the death cases with both variables for lags (lags 0 to 5) for single days. Lag 0 shows the effect of the present day's temperature and RH on that day's number of death cases (Guo et al. 2011; Kan et al. 2007). The relationship between weather variables and death cases of COVID-19 was analyzed using a spline function in the GAM and is presented through a correlation graph between response and exposure. Further, we performed a sensitivity analysis for examining the robustness of our results.

\section{Empirical results}

Descriptive statistics of COVID-19 daily death cases, air contaminating variables, and meteorological variables are presented in Table 1. From 23 February to 31 March 2020, there were a total of 11,591 death cases reported in Italy (Chustecka 2020). On average, there were 305 deaths due to COVID-19 per day.

In Italy, temperatures ranged from 282.15 to $291.53 \mathrm{~K}$ in the selected period. The average temperature in Milan, Northern Italy, is $288.59 \mathrm{~K}$. The temperature is measured on the Kelvin scale as it is thermodynamic. This scale is linear with zero points as it has absolute zero. The mean of relative humidity is $45 \%$, and the mean of absolute humidity is 4.56 $\mathrm{g} / \mathrm{m}^{3}$. The mean concentrations of air pollutants including $\mathrm{NH}_{3}, \mathrm{NO}_{2}, \mathrm{SO}_{2}, \mathrm{O}_{3}, \mathrm{PM}_{10}, \mathrm{CO}$, and $\mathrm{PM}_{2.5}$ were $44,22.7$, $6.52,64.85,41.52,0.74$, and $33.16 \mu \mathrm{g} / \mathrm{m}^{3}$, respectively. The relationship between daily death counts due to COVID-19 and temperature and meteorological data are presented in Fig. 1.

The figure shows that within the period from 23 February 2020 to 31 March 2020, the number of death cases reported showed a dramatic increase. The trend of temperature showed a fluctuating trend but with a minor decrease over the selected period. However, relative humidity and absolute humidity showed a slightly declining trend. The figure depicts a negative relationship between all meteorological factors (temperature, absolute humidity, and relative humidity) with COVID19 death cases.

The correlation coefficients among death counts of COVID-19, meteorological measures, and air pollutants are presented in Table 2 . The factors that showed a negative relationship with number of death cases reported are relative humidity (RH) $(r=-0.35), \mathrm{NO}_{2}(r=-0.36), \mathrm{CO}(r=-0.39)$, $\mathrm{SO}_{2}(r=-0.44), \mathrm{NH}_{3}(r=-0.16), \mathrm{PM}_{10}(r=-0.33), \mathrm{PM}_{2.5}(r$ $=-0.41)$, absolute humidity (AH) $(r=-0.18)$, and temperature $(r=-0.12)$. While a positive relationship is shown between COVID-19 death cases with ozone $\mathrm{O}_{3}(0.34)$.

In the above figures, the $x$ axis presents the concurrent day data, while the $y$ axis presents the predicted log relative risk (RR). Relative risk is a measure of the risk of COVID-19 deaths relative to the change in temperature. It acts as an intuitive way to analyze the risks between COVID-19 deaths and meteorological factors' variation in a comparative manner. This measure has been also applied in past studies for analyzing the relationship between climate and the COVID19 mortality rate (Ma et al. 2020; Jiang and Xu 2021). Figure 2 depicts a fluctuating but negative relationship between absolute humidity and death cases presented on the same day (lag 
Table 1 Basic summary statistics of the epidemiological and meteorological data

Meteorological and air contaminating factors

\begin{tabular}{|c|c|c|c|c|c|c|c|c|c|c|c|}
\hline & $\begin{array}{l}\text { COVID-19 } \\
\text { death cases }\end{array}$ & $\begin{array}{l}\text { Average } \\
\text { temp. (K) }\end{array}$ & RH (\%) & $\mathrm{AH}\left(\mathrm{g} / \mathrm{m}^{3}\right)$ & $\begin{array}{l}\mathrm{CO} \\
\left(\mathrm{mg} / \mathrm{m}^{3}\right)\end{array}$ & $\begin{array}{l}\mathrm{NH}_{3} \\
\left(\mathrm{ug} / \mathrm{m}^{3}\right)\end{array}$ & $\begin{array}{l}\mathrm{NO}_{2} \\
\left(\mathrm{ug} / \mathrm{m}^{3}\right)\end{array}$ & $\mathrm{PM}_{10}$ & $\begin{array}{l}\mathrm{SO}_{2} \\
\left(\mathrm{ug} / \mathrm{m}^{3}\right)\end{array}$ & $\begin{array}{l}\mathrm{O}_{3} \\
\left(\mathrm{ug} / \mathrm{m}^{3}\right)\end{array}$ & $\begin{array}{l}\mathrm{PM}_{2.5} \\
\left(\mathrm{ug} / \mathrm{m}^{3}\right)\end{array}$ \\
\hline Mean & 305 & 290.15 & 45.6 & 4.56 & 0.74 & 44.00 & 22.7 & 41.52 & 6.52 & 64.85 & 33.16 \\
\hline Min & 1 & 282.15 & 13.9 & 2.98 & 0.41 & 10.01 & 8.00 & 9.00 & 4.00 & 28 & 7.01 \\
\hline Median & 181 & 290.15 & 58.2 & 4.50 & 0.74 & 40.00 & 18.00 & 34.00 & 6.00 & 55 & 34.00 \\
\hline Max & 971 & 291.53 & 91.1 & 8.56 & 1.02 & 92.02 & 64.00 & 87.00 & 11.00 & 84 & 68.00 \\
\hline $\mathrm{P}_{25}$ & 14.75 & 272.71 & 22.2 & 3.15 & 0.65 & 26.00 & 15.00 & 28.00 & 3.00 & 45 & 24.00 \\
\hline $\mathrm{P}_{75}$ & 621 & 285.43 & 57.2 & 5.23 & 0.90 & 58.00 & 58.00 & 61.00 & 7.00 & 83 & 57.00 \\
\hline
\end{tabular}

COVID-19 DC, coronavirus death cases 2020; Min, minimum; Max, Maximum; $P_{75}, 75$ th percentile; $P_{25}, 25$ th percentile; $P M_{10}$, particulate matter with aerodynamic diameter $\leq 10 \mu \mathrm{m} ; \mathrm{PM}_{2.5}$, particulate matter with aerodynamic diameter $\leq 2.5 \mu \mathrm{m} ; \mathrm{O}_{3}$, ozone; $\mathrm{NO}_{2}$, nitrogen dioxide; $\mathrm{CO}$, carbon monoxide; $\mathrm{SO}_{2}$, sulfur dioxide, $\mathrm{RH}$, relative humidity; $\mathrm{AH}$, absolute humidity; $\mathrm{NH}_{3}$, ammonia

0 ). As the level of absolute humidity decreases, a significant increase in the number of deaths can be observed. Figure 3 shows the relationship between relative humidity and death cases; it is evident that in the selected period, the number of death cases shows an increase, with a slight decrease in relative humidity. Thus, it presents a negative relationship between relative humidity and COVID-19 death cases. Figure 4 presents the relationship between temperature and COVID-19 death cases, and it can be observed that with the decrease in temperature, the number of death cases is showing a slightly increasing trend. Overall, the temperature shows a linear negative trend, but absolute and relative humidity shows a strong negative trend with the COVID-19 death cases. To find evidence for these findings, lag effects were applied in the following analysis.
Figure 5 depicts the percentage changes in death cases reported due to COVID-19, with each unit increase in meteorological factor levels with selected different lag days in the models.

The percentage change with $95 \%$ confidence interval of COVID-19 death cases with per one unit rise in meteorological factors for various lag days in the models in Milan, Northern Italy, from 23 February to 31 March 2020. As per the results, the COVID-19 death cases 2020, temperature, absolute humidity, and relative humidity after controlling the effects of air contaminating factors show per one unit increase in temperature caused a $2.75 \%$ (95\% confidence interval; $0.46 \%, 5.21 \%$ ) decrease in COVID-19 death cases in lag 1 . In the case of relative humidity, per one unit increase was associated with a decrease in COVID-19 death cases in lag 4

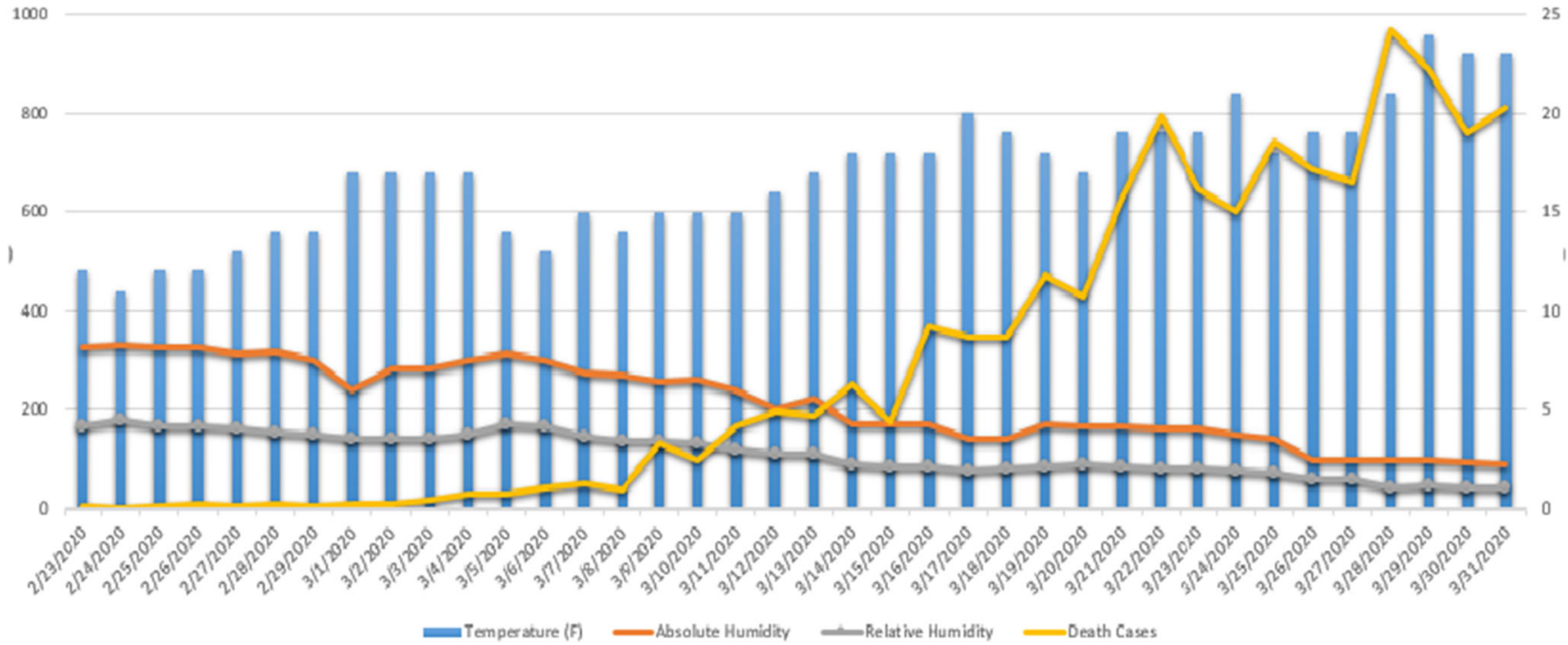

Fig. 1 Relationship between COVID-19 death cases and temperature, relative humidity, and meteorological factors 
Table 2 Spearman's correlation between air pollutants, temperature, and relative and absolute humidity and COVID-19 death cases

\begin{tabular}{|c|c|c|c|c|c|c|c|c|c|c|c|}
\hline & Death cases & Temp & RH & $\mathrm{AH}$ & $\mathrm{NH}_{3}$ & $\mathrm{PM}_{2.5}$ & $\mathrm{PM}_{10}$ & $\mathrm{NO}_{2}$ & $\mathrm{SO}_{2}$ & $\mathrm{CO}$ & $\mathrm{O}_{3}$ \\
\hline Death cases & $1.00 *$ & & & & & & & & & & \\
\hline Temp & $-0.12 *$ & 1.00 & & & & & & & & & \\
\hline $\mathrm{RH}$ & $-0.35^{*}$ & -0.14 & 1.00 & & & & & & & & \\
\hline $\mathrm{AH}$ & $-0.18^{*}$ & -0.34 & 0.45 & 1.00 & & & & & & & \\
\hline NH3 & $-0.16^{*}$ & $0.57 *$ & $0.28 *$ & 0.12 & 1.00 & & & & & & \\
\hline $\mathrm{PM}_{2.5}$ & $-0.41 *$ & 0.07 & -0.31 & 0.34 & -0.04 & 1.00 & & & & & \\
\hline $\mathrm{PM}_{10}$ & $-0.33 *$ & 0.09 & -0.33 & 0.14 & 0.03 & $0.63 *$ & 1.00 & & & & \\
\hline $\mathrm{NO}_{2}$ & $-0.36^{*}$ & 0.18 & $-0.29^{*}$ & 0.07 & -0.08 & $0.54 *$ & $0.50^{*}$ & 1.00 & & & \\
\hline $\mathrm{SO}_{2}$ & $-0.44 *$ & $0.34 *$ & $-0.54^{*}$ & 0.02 & 0.01 & $0.27 *$ & $0.36^{*}$ & $0.67 *$ & 1.00 & & \\
\hline $\mathrm{CO}$ & $-0.39 *$ & $0.41 *$ & -0.03 & 0.16 & $0.26^{*}$ & $0.15^{*}$ & $0.43 *$ & $0.55^{*}$ & $0.41^{*}$ & 1.00 & \\
\hline $\mathrm{O}_{3}$ & $0.34^{*}$ & 0.06 & $-0.68^{*}$ & 0.18 & -0.30 & 0.36 & 0.31 & $0.21 *$ & $0.39 *$ & 0.01 & 1.00 \\
\hline
\end{tabular}

COVID-19 DC, corona virus death cases $2020 ; P_{75}, 75$ th percentile; $P_{25}, 25$ th percentile; $P M_{10}$, particulate matter with aerodynamic diameter $\leq 10 \mu$ m; $P M_{2.5}$, particulate matter with aerodynamic diameter $\leq 2.5 \mu \mathrm{m} ; \mathrm{O}_{3}$, ozone; $\mathrm{NO}_{2}$, nitrogen dioxide; $\mathrm{CO}$, carbon monoxide; $\mathrm{SO}_{2}$, sulfur dioxide; $\mathrm{RH}$, relative humidity; $\mathrm{AH}$, absolute humidity; $\mathrm{NH}_{3}$, ammonia. ${ }^{*} p<0.05$

[3.01\% (95\% CI: $0.57 \%, 5.31 \%)]$. For one unit increase in absolute humidity, a decrease in COVID-19 deaths is observed in lag 1 [3.54\% (95\% CI: $0.65 \%, 5.81 \%)]$. Thus, our results confirm the presence of a negative relationship between meteorological factors (absolute humidity, relative humidity, and temperature) and COVID-19 death cases.

\section{Sensitivity analyses}

In this study, for checking the robustness of our model, we performed a sensitivity analysis. First, a GAM model is developed in which date was considered as spline functions, and the effect of mean relative humidity and the average temperature on COVID-19 death cases is examined by using varying lag days. The lag days are composed of lag 1 (lag 1 day), lag 3 (lag 3 day), lag 5 (lag 5 day), and lag 7 (lag 7 day) for capturing lagged and immediate effects. As past meteorological studies highlighted, the robustness of results can be measured by using different lag days in a sensitivity analysis (Ward et al. 2020; Ceylan 2020) (Table 3).

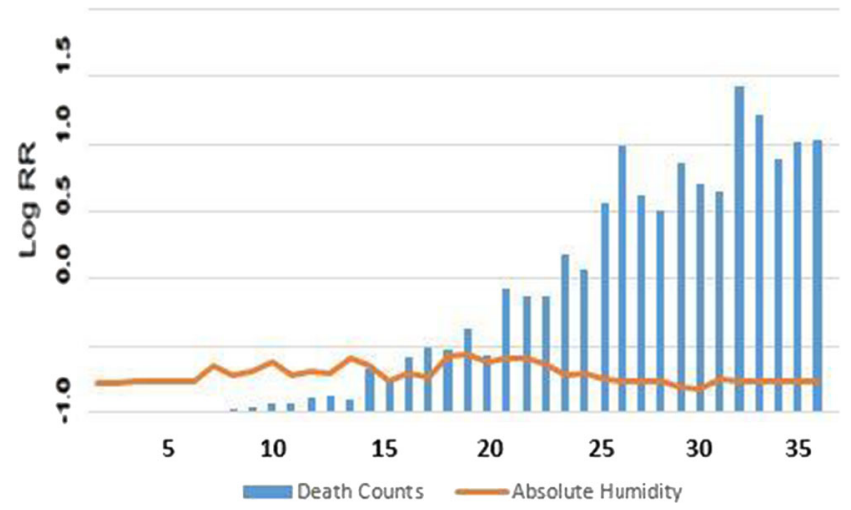

Fig. 2 Graph between absolute humidity and death cases
Secondly, as Italy has varying climatic conditions with reference to different areas and some areas in Northern Italy reported significantly high COVID-19 death cases due to reasons not related to meteorological factors, therefore, we excluded COVID-19 highly affected areas: Brera, Conca del Naviglio, Guastalla, Porta Sempione, and Door Pincer. Recent meteorological studies have also excluded COVID19 highly affected regions for developing a balanced sample for performing sensitivity analysis (Adekunle et al. 2020; Mandal et al. 2020).

Finally, we excluded some confounding variables including relative humidity $(\mathrm{RH})$ and air pollutants $\left(\mathrm{O}_{3}\right.$, ozone; $\mathrm{NO}_{2}$, nitrogen dioxide; $\mathrm{CO}$, carbon monoxide; $\mathrm{SO}_{2}$, sulfur dioxide; $\mathrm{NH}_{3}$, ammonia) from the GAM model as they may influence COVID-19 mortality rate. Recent meteorological literature on COVID-19 also followed the same approach in the GAM model for conducting a sensitivity analysis (Wu et al. 2020; Heibati et al. 2020). Thus, we evaluated the robustness of our results by applying a sensitivity test on a balanced GAM model.

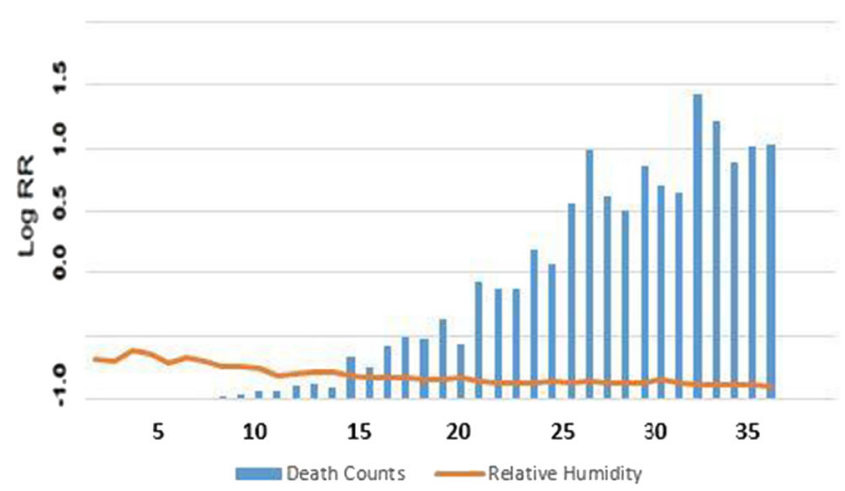

Fig. 3 Graph between relative humidity and death cases 


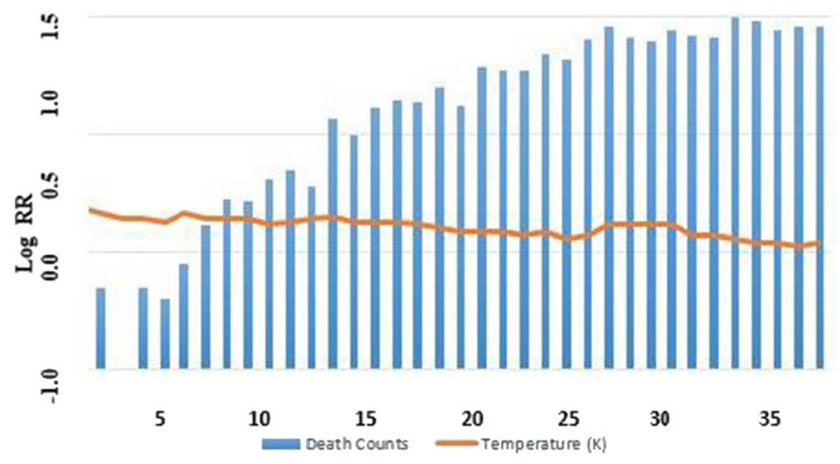

Fig. 4 Graph between temperature and death cases

The results of sensitivity analysis presented the lagged effects and revealed that temperature and absolute humidity share a significant and negative relationship with the COVID-19 death cases. The results of sensitivity analyses after comparison with the study model results revealed that our model was robust.

\section{Discussion}

The existing literature has a limited number of studies exploring the influence of varying weather conditions on the COVID-19 death counts. However, no analytical and quantitative research is conducted particularly from the perspective of inspecting the relationship between three meteorological factors (temperature, absolute humidity, and relative humidity) and the COVID-19 mortality rate in Milan, Italy, during the peak period of this disease. To fill this research gap, our research study primarily focused on examining the linkage between COVID-19 death cases and meteorological factors. The key findings depict a significant negative relationship
Table 3 Sensitivity analysis of the meteorological effects on COVID19 death cases

\begin{tabular}{lllll}
\hline Model & Estimate & Standard error & $Z$ value & $p$ value \\
\hline Model 1 & & & & \\
Lag 1 day & & & & \\
Absolute humidity & -0.006 & 0.001 & -12.021 & $<.001$ \\
Temperature & -0.004 & 0.002 & -11.040 & $<.001$ \\
Model 3 & & & & \\
Lag 3 day & & & & \\
Absolute humidity & -0.003 & 0.001 & -5.106 & $<.001$ \\
Temperature & -0.002 & 0.001 & -4.451 & $<.001$ \\
Model 5 & & & & \\
Lag 5 day & & & & \\
Absolute humidity & -0.075 & 0.002 & -3.124 & $<.001$ \\
Temperature & -0.012 & 0.001 & -4.225 & $<.001$ \\
Model 7 & & & & \\
Lag 7 day & & & & \\
Absolute humidity & -0.007 & 0.003 & -5.421 & $<.001$ \\
Temperature & -0.010 & 0.002 & -3.021 & $<.001$ \\
\hline
\end{tabular}

between temperature, relative humidity, and absolute humidity with the daily mortality rate of COVID-19. This outcome is in line with past studies which reported that high humidity and temperature decrease the transmission of viral diseases (Lipsitch and Viboud 2009; Shaman and Kohn 2009).

Our findings highlighted that these meteorological factors should be carefully analyzed for understanding all possible reasons behind the increase in COVID-19 death counts. One of the logical reasons behind this argument is reported by past studies that viruses remain more stable in low temperatures. Further, the respiratory droplets serve as virus containers, and

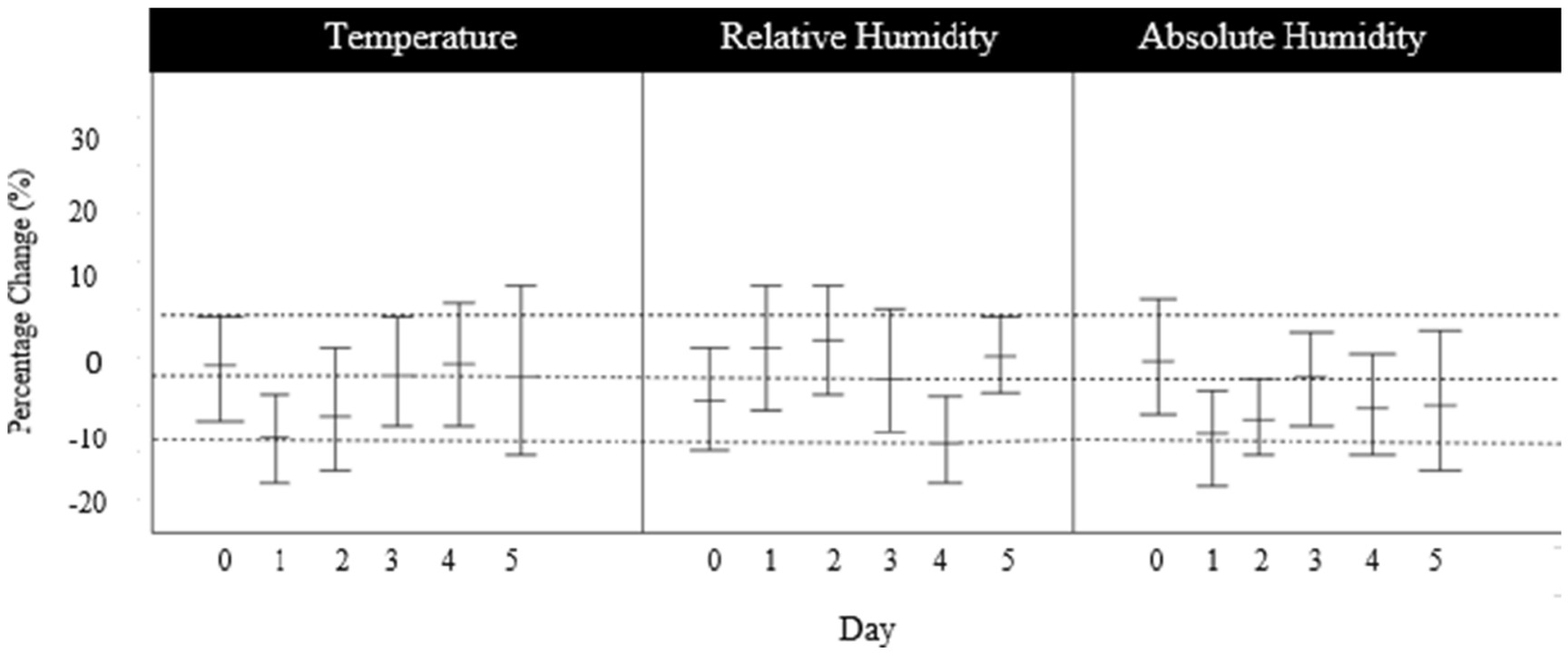

Fig. 5 Percentage changes in COVID-19 death cases with meteorological factor levels at different lag days 
it causes them to remain in the air for longer periods during winters (Lowen et al. 2008; Tellier 2009). In addition to this, cold weather weakens human immunity, and this makes humans more vulnerable to the virus (Chen et al. 2017a, 2017b; Kudo et al. 2019). These reasons also serve as an argument to claim that COVID-19 virus transmission will reduce with the increase in humidity and temperature (Shi et al. 2020; Wang et al. 2020a, b, c).

Additionally, the most recent publications on COVID-19 revealed that temperature and humidity are significant variables that directly affect the transmission of COVID-19, but their conclusions are distinctive in some aspects (Wang et al. 2020a, b, c; Oliveiros et al. 2020). For instance, the study of Cai et al. (2020) did not find any evidence confirming the linkage between daily mean temperature and the growth rate of the plague in both Wuhan and Hunan, two renowned cities of China. On the contrary, our study found a significant negative relationship between temperature and humidity on the daily death counts. Our study suggests that with a decrease in temperature, the number of death counts showed an increase. This outcome finds evidence in past studies such as Iqbal et al. (2020), reporting a decline in COVID-19 spread with an increase in the temperature. Further, Bashir et al. (2020) also found similar results for a study in NY, USA. They reported that total COVID-19 cases were significantly linked with average temperature changes $(r=0.379 ; p<0.10)$. The findings of these research studies are comparable with our findings. Moreover, Şahin (2020) found that temperature inversely correlates with COVID-19 cases in Turkey. Prata et al. (2020) also found a negative and linear relationship between temperature and COVID-19 cases $(p<0.05 ; r=-0.400)$. Further, Shi et al. (2020) also reported that the incidence of COVID-19 was reduced when temperatures go above 8 to $10^{\circ} \mathrm{C}$. Similarly, Ma et al. (2020) found a nonlinear relationship between COVID-19 mortality and temperature. They found that for every $1{ }^{\circ} \mathrm{C}$ increase in temperature, the COVID-19 death cases decreased by $12.3 \%$. To corroborate our results, it is significant to highlight that lower temperatures lead to increasing COVID-19 mortality rates. Thus, our findings are consistent with several past analytical studies that reported that a decrease in temperature causes the increased mortality of respiratory infectious diseases (Ghalhari and Mayvaneh 2016; Dadbakhsh et al. 2017; Gomez-Acebo et al. 2013).

Our results are also strengthened by the findings of past studies that claimed low temperature is the most suitable medium for the spread of viral diseases, such as Shephard and Shek (1998), conducting a case study of immune function and cold exposure and concluding that immune function could be repressed due to lower temperature. Similarly, Davis et al. (2016) reported that cold and low humidity conditions are vital contributors to the increasing number of respiratory infectious patients. Since SARS-CoV-2 is very sensitive to heat, and the high temperature seems likely to be the main hurdle for its survival, not to indicate the valuable factors for virus transference like poor ventilation system and indoor gathering in the cold season ( $\mathrm{Hu}$ et al. 2020).

In the case of absolute and relative humidity, we found a significant and negative relationship with COVID-19 death cases. Absolute and relative humidity are two of the most frequently used variables for understanding humidity-related mortality rates (Wang et al. 2020a, b, c). Our results indicated that absolute humidity decreases over the selected period, while the number of COVID-19 death cases shows an inclining trend. Thus, absolute humidity shares a negative relationship with the COVID-19 mortality rate. The findings are supported by past research studies, such as Ma et al. (2020), examining the relationship between absolute humidity and COVID-19 death counts in South America and finding a negative relationship. Similarly, Liu et al. $(2020 a, b)$ found a negative relationship between humidity and temperature with COVID-19 death cases in 30 cities in China. This result found support in the past findings of Biktasheva (2020), who reported that humidity negatively correlates with COVID-19 mortality and morbidity in German federal states. Likewise, Ma et al. (2020) also stated a negative relationship between humidity and COVID-19 death counts in Wuhan, China. Similarly, Wu et al. (2020) found a negative relationship between humidity and temperature with daily new cases and death cases of COVID-19 in 166 countries. Further, this finding is also in line with the results of Oliveiros et al. (2020) and Wang et al. (2020a, b, c), who reported that an increase in humidity and temperature results in a decrease in COVID-19 transmission.

The logical grounds behind this finding can be found in a detailed study of 25 years that claimed humidity as one of the prominent determinants of mortality, and low humidity might result in increased mortality rates, mainly in the case of viral diseases (Barreca 2012). Likewise, Lowen et al. (2007) stated that intake of dry air could damage the epithelial part of the body and would ultimately result in permitting the host agent to cause respiratory virus infection within the body. Moreover, Barreca and Shimshack (2012) investigated weather conditions and their relationship with influenza mortality for the period of 1973 to 2002 . They found humidity levels lesser than $6 \mathrm{~g}$ of water vapor are associated with an increase in influenza mortality. As the construction of droplet nuclei is essential to transference, but respired droplets settle very quickly at higher humidity levels, so it becomes difficult to impact the influenza virus spread. In view of recent studies, the results of Oliveiros et al. (2020) revealed that COVID-19 transmission will reduce in the spring and summer seasons with the rise in temperature and humidity levels. Likewise, Wang et al. (2020a, b, c) also found that a $1^{\circ}$ rise in temperature and humidity lowers COVID-19 transmission rates.

Therefore, the increased mortality rate of COVID-19 might be linked with the low humidity range in the winter season. 
This study established the robustness of the GAM model used in this research by performing a sensitivity analysis on a model with different lag days, exclusion of highly COVID-19 affected district, and exclusion of potential confounding variables, which may influence the COVID-19 mortality rate in Milan, Italy. The sensitivity analysis revealed that temperature and absolute humidity share a significant and negative relationship with COVID-19 death cases. The results of the sensitivity test prove that our model was robust.

\section{Conclusion}

This research contributes to the existing studies, as this is the first quantitative study conducted to examine the impact of humidity and temperature on the daily mortality of COVID-19 by selecting the sample data of the Italian population. Our outcomes reveal that all our selected meteorological variables including, absolute humidity, relative humidity, and temperature are significantly and negatively correlated with the death cases of COVID-19. This study thus sheds light on the significance of considering temperature and humidity for getting deeper insights into the COVID-19 mortality rates. The study contributes both theoretically and practically to the field of pandemic management in Italy. The findings herewith enhance our understanding and may facilitate adopting appropriate measures in developing efficient policies. Further, our results shall lead to an enhanced understanding of meteorological factors responsible for the increase in COVID-19 mortality across the most infected regions in the world. The findings may also assist weather forecasting committees in tackling air quality scenarios in the future. Moreover, the results may also help to recognize similar climate conditions that further assist in understanding the linkage between COVID-19 mortality and meteorological factors. The sensitivity analysis was performed, and it revealed a significant negative relationship of temperature and absolute humidity with COVID-19 death cases and proved that our model results were robust.

Thus, this study has contributed ominously in the field of research by finding a significant impact of temperature and humidity on the COVID-19 mortality rates by adopting a well-known distributed lag nonlinear threshold model in the context of the northern region of Italy. The research highlights new insights on the association between COVID-19 mortality rates and meteorological factors. First, the results indicated that weather parameters are integral and significant in predicting and understanding COVID19 and its effect on COVID-19 death cases. People living in colder regions in the world should consider practical measures to prevent the COVID-19 spread. The results also highlight that all countries should focus on having anti-epidemic policies if this COVID-19 virus exists for a longer period. To date, the relationship between the COVID-19 death counts and meteorological factors is still unexplored concerning Milan, Italy, and the selected COVID-19 peak time. Therefore, the second contribution of this study is the application of a robust statistical analysis of the semiparametric generalized additive model (GAM) on the data collected in the peak time of reported COVID-19 death cases in Milan, Italy. This ensures an examination of the accurate effect of temperature and humidity on daily COVID-19 death cases. Third, the findings of this study will be a useful supplement to assist health care policymakers to enhance their understanding of COVID-19 and its dependency on weather conditions. The results might help policymakers in developing active response strategies for controlling COVID-19 mortality rates because of changing weather conditions. Also, it will facilitate researchers to develop more critical temperature-related emergency plans and guide policymakers in the formation of informative adaptation strategies. Future researchers may consider engaging themselves in the inspection of epidemiological data more widely to investigate the imported cases and local spread of COVID-19, particularly by focusing on government COVID-19 prevention strategies.

However, some limitations are also discussed. First, this study primarily focuses only on the northern region of Italy, and conclusions are based on the sample data of a very limited area which might be inappropriate to represent the perfect possible pattern of weather-mortality linkage in the southern side of Italy or all over the world. Second, it is a well-known fact that the impact of weather on mortality rates is dependent on socio-demographical and environmental patterns, which were not addressed. Further, an in-depth research study on all these factors will enable us to understand the philosophy of temperature and humidity-mortality linkage. The findings can assist the rapidly growing COVID-19 mortality rates based on dynamic weather conditions. These findings could also be helpful for intervention planning for future pandemics, counting a potential future COVID-19 outbreak.

Acknowledgements We thank Dr. Ather Azim Khan (Associate Dean, UCP Business School) for his guidance in improving the structure of the paper. We are also grateful for the insightful comments offered by the anonymous reviewers for improving our paper.

Availability of data and materials The datasets used in preparing this article are available in the following repositories.

1. Weather Underground (https://www.wunderground.com/).

2. World Air Quality Index (AQI) (https://aqicn.org/city/italy/ lombardia/milano-pascal-citta-studi/).

3. Statista's website (https://www.statista.com/statistics/1109295/ provinces-with-most-coronavirus-cases-in-italy/).

Author contribution AK drafted the manuscript, collected data, and performed data analysis. Dr. FM drafted the manuscript, supervised research work, and improved the methodology and discussion part. AA improved data analysis and improved the conclusion part. All authors read and approved the final manuscript. 


\section{Declarations}

Ethical approval and consent to participate Not applicable.

Consent for publication Not applicable.

Competing interests The authors declare no competing interests.

\section{References}

Adekunle IA, Tella SA, Oyesiku KO, Oseni IO (2020) Spatio-temporal analysis of meteorological factors in abating the spread of COVID19 in Africa. Heliyon 6(8):e04749

Ahmad M, Ur Rahman Z, Hong L, Khan S, Khan Z, Naeem Khan M (2018) Impact of environmental quality variables and socioeconomic factors on human health: empirical evidence from China. Pollution 4(4):571-579

Anderson BG, Bell ML (2009) Weather-related mortality: how heat, cold, and heat waves affect mortality in the United States. Epidemiology (Cambridge, Mass) 20(2):205

Araveeporn A (2019) Estimating conditional heteroscedastic nonlinear autoregressive model by using smoothing spline and penalized spline methods. Songklanakarin J Sci Technol 41(4)

Barreca AI (2012) Climate change, humidity, and mortality in the United States. J Environ Econ Manag 63(1):19-34

Barreca AI, Shimshack JP (2012) Absolute humidity, temperature, and influenza mortality: 30 years of county-level evidence from the United States. Am J Epidemiol 176(suppl_7):S114-S122

Bashir MF, Ma B, Komal B, Bashir MA, Tan D, Bashir M (2020) Correlation between climate indicators and COVID-19 pandemic in New York, USA. Sci Total Environ 728:138835

Boccia S, Ricciardi W, Ioannidis JP (2020) What other countries can learn from Italy during the COVID-19 pandemic. JAMA Intern Med 180(7):927-928

Biktasheva IV (2020) Role of a habitat's air humidity in COVID-19 mortality. Sci Total Environ 736:138763

Bozdogan H (1987) Model selection and Akaike information criterion (AIC) - the general-theory and its analytical extensions. Psychometrika 52:345-370

Breitner S, Wolf K, Devlin RB, Diaz-Sanchez D, Peters A, Schneider A (2014) Short-term effects of air temperature on mortality and effect modification by air pollution in three cities of Bavaria, Germany: a time-series analysis. Sci Total Environ 485:49-61

Cai Y, Huang T, Liu X, Xu G (2020). The effects of "Fangcang, Huoshenshan, and Leishenshan" makeshift hospitals and temperature on the mortality of COVID-19. MedRxiv.

Carlos WG, Dela Cruz CS, Cao B, Pasnick S, Jamil S (2020) Novel Wuhan (2019-nCoV) coronavirus. Am J Respir Crit Care Med 201(4):P7-P8

Ceylan Z (2020). Insights into the relationship between weather parameters and COVID-19 outbreak in Lombardy, Italy. International Journal of Healthcare Management, 1-9.

Chen G, Li S, Zhang Y, Zhang W, Li D, Wei X, He Y, Bell ML, Williams G, Marks GB, Jalaludin B, Abramson MJ, Guo Y (2017a) Effects of ambient PM1 air pollution on daily emergency hospital visits in China: an epidemiological study. The Lancet Planetary Health 1(6):e221-e229

Chen G, Zhang W, Li S, Zhang Y, Williams G, Huxley R, Guo Y (2017b) The impact of ambient fine particles on influenza transmission and the modification effects of temperature in China: a multi-city study. Environ Int 98:82-88
Chien LC, Chen LW (2020) Meteorological impacts on the incidence of COVID-19 in the US. Stoch Environ Res Risk Assess 34(10):16751680

Chustecka Z (2020). Medscape medical news. Retrieved from Medscape: https://www.medscape.com/viewarticle/927753

Dadbakhsh M, Khanjani N, Bahrampour A, Haghighi PS (2017) Death from respiratory diseases and temperature in Shiraz, Iran (20062011). Int J Biometeorol 61(2):239-246

Davis RE, Dougherty E, McArthur C, Huang QS, Baker MG (2016) Cold, dry air is associated with influenza and pneumonia mortality in Auckland, New Zealand. Influenza Other Respir Viruses 10(4): 310-313

Ficetola GF, Rubolini D (2020). Climate affects global patterns of COVID-19 early outbreak dynamics. MedRxiv

Fischer PH, Marra M, Ameling CB, Hoek G, Beelen R, de Hoogh K, Houthuijs D (2015) Air pollution and mortality in seven million adults: the Dutch Environmental Longitudinal Study (DUELS). Environ Health Perspect 123(7):697-704

Gasparrini A, Armstrong B, Kenward MG (2010) Distributed lag nonlinear models. Stat Med 29(21):2224-2234

Ghalhari GF, Mayvaneh F (2016) Effect of air temperature and universal thermal climate index on respiratory diseases mortality in Mashhad, Iran. Archives of Iranian Medicine (AIM) 19(9)

Gomez-Acebo I, Llorca J, Dierssen T (2013) Cold-related mortality due to cardiovascular diseases, respiratory diseases, and cancer: a casecrossover study. Public Health 127(3):252-258

Gorbalenya AE, Baker SC, Baric RS, de Groot RJ, Drosten C, Gulyaeva AA, et al. (2020). Severe acute respiratory syndrome-related coronavirus: the species and its viruses - a statement of the Coronavirus Study Group. BioRxiv

Gralinski LE, Menachery VD (2020) Return of the coronavirus: 2019nCoV. Viruses 12(2):135

Guo Y, Barnett AG, Pan X, Yu W, Tong S (2011) The impact of temperature on mortality in Tianjin, China: a case-crossover design with a distributed lag nonlinear model. Environ Health Perspect 119(12): $1719-1725$

Heibati B, Wang W, Ryti N, Dominici F, Ducatman A, Zhang Z, Jaakkola J (2020). Weather conditions and COVID-19 incidence in a cold climate: a time-series study in Finland, 8, 1-7.

Hu X, An T, Situ B, Hu Y, Ou Z, Li Q, He X, Zhang Y, Tian P, Sun D, Rui Y, Wang Q, Ding D, Zheng L (2020) Heat inactivation of serum interferes with the immunoanalysis of antibodies to SARS-CoV-2. J Clin Lab Anal 34(9):e23411

Iqbal N, Fareed Z, Shahzad F, He X, Shahzad U, Lina M (2020) The nexus between COVID-19, temperature and exchange rate in Wuhan city: new findings from partial and multiple wavelet coherence. Sci Total Environ 729:138916

Jiang Y, Xu J (2021) The association between COVID-19 deaths and short-term ambient air pollution/meteorological condition exposure: a retrospective study from Wuhan, China. Air Qual Atmos Health 14(1): $1-5$

Kan H, London SJ, Chen H, Song G, Chen G, Jiang L, Zhao N, Zhang Y, Chen B (2007) Diurnal temperature range and daily mortality in Shanghai, China. Environ Res 103(3):424-431

Khursheed A, Fatima M, Mustafa F, Lodhi RN, Akhtar A (2020a) An empirical analysis of the factors that influence social entrepreneurship: a gender approach. Management Letters / Management Notebooks 21(2): 1-14

Khursheed A, Naeem M, Ahmed S, Mustafa F (2020b) Adaptive market hypothesis: an empirical analysis of time-varying market efficiency of cryptocurrencies. Cogent Economics \& Finance 8(1):1-15

Kodera S, Rashed EA, Hirata A (2020) Correlation between COVID-19 morbidity and mortality rates in Japan and local population density, temperature, and absolute humidity. Int J Environ Res Public Health 17(15):5477 
Kudo E, Song E, Yockey LJ, Rakib T, Wong PW, Homer RJ, Iwasaki A (2019) Low ambient humidity impairs barrier function and innate resistance against influenza infection. Proc Natl Acad Sci 116(22): 10905-10910

Leung NY, Bulterys MA, Bulterys PL (2020). Predictors of COVID-19 incidence, mortality, and epidemic growth rate at the country level. MedRxiv

Li Q, Guan X, Wu P, Wang X, Zhou L, Tong Y, Ren R, Leung KSM, Lau EHY, Wong JY, Xing X, Xiang N, Wu Y, Li C, Chen Q, Li D, Liu T, Zhao J, Liu M, Tu W, Chen C, Jin L, Yang R, Wang Q, Zhou S, Wang R, Liu H, Luo Y, Liu Y, Shao G, Li H, Tao Z, Yang Y, Deng Z, Liu B, Ma Z, Zhang Y, Shi G, Lam TTY, Wu JT, Gao GF, Cowling BJ, Yang B, Leung GM, Feng Z (2020) Early transmission dynamics in Wuhan, China, of novel coronavirus-infected pneumonia. N Engl J Med 382:1199-1207

Lin J, Huang W, Wen M, Li D, Ma S, Hua J, Zhang Q (2020) Containing the spread of coronavirus disease 2019 (COVID-19): meteorological factors and control strategies. Sci Total Environ 744:140935

Lipsitch M, Viboud C (2009) Influenza seasonality: lifting the fog. Proc Natl Acad Sci 106(10):3645-3646

Liu J, Zhou J, Yao J, Zhang X, Li L, Xu X, He X, Wang B, Fu S, Niu T, Yan J, Shi Y, Ren X, Niu J, Zhu W, Li S, Luo B, Zhang K (2020a) Impact of meteorological factors on the COVID-19 transmission: a multi-city study in China. Sci Total Environ 726:138513

Liu Q, Tan ZM, Sun J, Hou Y, Fu C, Wu Z (2020b) Changing rapid weather variability increases influenza epidemic risk in a warming climate. Environ Res Lett 15(4):044004

Liuab X, Huangab J, Li C, Zhaob Y, Wang D, Huanga Z, Yang K (2021) The role of seasonality in the spread of COVID-19 pandemic. Environ Res 195:110874. https://doi.org/10.1016/j.envres.2021. 110874

Lolli S, Chen YC, Wang SH, Vivone G (2020) Impact of meteorological conditions and air pollution on COVID-19 pandemic transmission in Italy. Sci Rep 10(1):1-15

Lowen AC, Mubareka S, Steel J, Palese P (2007) Influenza virus transmission is dependent on relative humidity and temperature. PLoS Pathog 3(10):e151

Lowen AC, Steel J, Mubareka S, Palese P (2008) High temperature (30 C) blocks aerosol but does not contact transmission of influenza virus. J Virol 82(11):5650-5652

Lu H, Stratton CW, Tang YW (2020). The outbreak of pneumonia of unknown etiology in Wuhan China: the mystery and the miracle. Journal of Medical Virology.

Luo Z, Wahba G, Johnson DR (1998) Spatial-temporal analysis of temperature using smoothing spline ANOVA. J Clim 11(1):18-28

Luo Y, Yan J, McClure S (2021) Distribution of the environmental and socioeconomic risk factors on COVID-19 death rate across continental USA: a spatial nonlinear analysis. Environ Sci Pollut Res 28(6):6587-6599

Ma Y, Zhao Y, Liu J, He X, Wang B, Fu S, Luo B (2020) Effects of temperature variation and humidity on the death of COVID-19 in Wuhan, China. Sci Total Environ 724:138226

Mahmud AS, Martinez PP, He J, Baker RE (2020) The impact of climate change on vaccine-preventable diseases: insights from current research and new directions. Current Environmental Health Reports: $1-8$

Mandal M, Jana S, Nandi SK, Khatua A, Adak S, Kar TK (2020) A model based study on the dynamics of COVID-19: prediction and control. Chaos, Solitons Fractals 136:109889

Morin CW, Comrie AC, Ernst K (2013) Climate and dengue transmission: evidence and implications. Environ Health Perspect 121(1112):1264-1272

Mustafa F, Khursheed A, Fatima M (2018) Impact of global financial crisis on financially innovative microfinance institutions in South Asia. Financial Innovation 4(1):1-11
Mustafa F, Khursheed A, Rizvi SMU, Zahid A, Akhtar A (2021) Factors influencing online learning of university students under the COVID19 pandemic. IJERI: International Journal of Educational Research and Innovation 15:342-359

Nasir A, Khursheed A, Ali K, Mustafa F (2020) A Markov decision process model for optimal trade of options using statistical data. Comput Econ:1-20

O'Gorman PA, Muller CJ (2010) How closely do changes in surface and column water vapor follow Clausius-Clapeyron scaling in climate change simulations? Environ Res Lett 5(2):025207

Oliveiros B, Caramelo L, Ferreira NC, Caramelo F (2020). Role of temperature and humidity in the modulation of the doubling time of COVID-19 cases. medRxiv

Pan J, Yao Y, Liu Z, Meng X, Ji JS, Qiu Y, Wang W, Zhang L, Wang W, Kan H (2021) Warmer weather unlikely to reduce the COVID-19 transmission: an ecological study in 202 locations in 8 countries. Sci Total Environ 753:142272

Pani SK, Lin NH, RavindraBabu S (2020) Association of COVID-19 pandemic with meteorological parameters over Singapore. Sci Total Environ 740:140112

Pinheiro SDLL, Saldiva PHN, Schwartz J, Zanobetti A (2014) Isolated and synergistic effects of $\mathrm{PM}_{10}$ and average temperature on cardiovascular and respiratory mortality. Rev Saude Publica 48(6):881888

Prata DN, Rodrigues W, Bermejo PH (2020) Temperature significantly changes COVID-19 transmission in (sub) tropical cities of Brazil. Sci Total Environ 729:138862

Qi H, Xiao S, Shi R, Ward MP, Chen Y, Tu W, Su Q, Wang W, Wang X, Zhang Z (2020) COVID-19 transmission in Mainland China is associated withtemperature and humidity: a time-series analysis. Sci Total Environ 728:1-6

Rasmussen SA, Jamieson DJ (2020) Coronavirus disease 2019 (COVID19) and pregnancy: responding to a rapidly evolving situation. Obstet Gynecol 135:999-1002

Ravindra K, Rattan P, Mor S, Aggarwal AN (2019) Generalized additive models: building evidence of air pollution, climate change, and human health. Environ Int 132:104987

Şahin M (2020) Impact of weather on COVID-19 pandemic in Turkey. Sci Total Environ 728:138810

Shaman J, Kohn M (2009) Absolute humidity modulates influenza survival, transmission, and seasonality. Proc Natl Acad Sci 106(9): 3243-3248

Shephard RJ, Shek PN (1998) Cold exposure and immune function. Can J Physiol Pharmacol 76(9):828-836

Shi P, Dong Y, Yan H, Zhao C, Li X, Liu W, He M, Tang S, Xi S (2020) Impact of temperature on the dynamics of the COVID-19 outbreak in China. Sci Total Environ 728:138890. https://doi.org/10.1016/j. scitotenv.2020.138890

Signorelli C, Scognamiglio T, Odone A (2020) COVID-19 in Italy: impact of containment measures and prevalence estimates of infection in thegeneral population. Acta Biomed 91(3-S):175-179

Silvia AS (2020) Italy's death toll surpasses 10,000 as prime minister warns of rising 'nationalist instincts'. Retrieved from CNBC: https://www.cnbc.com/2020/03/30/italy-coronavirus-deaths-above10000-conte-warns-against-anti-eu-sentiment.html

Smit AJ, Fitchett JM, Engelbrecht FA, Scholes RJ, Dzhivhuho G, Sweijd NA (2020) Winter is coming: a southern hemisphere perspective of the environmental drivers of SARS-CoV-2 and the potential seasonality of COVID-19. Int J Environ Res Public Health 17(16):5634

Tanne JH, Hayasaki E, Zastrow M, Pulla P, Smith P, Rada AG (2020) COVID-19: how doctors and healthcare systems are tackling coronavirus worldwide. Bmj 368

Teklehaimanot HD, Lipsitch M, Teklehaimanot A, Schwartz J (2004) Weather-based prediction of Plasmodium falciparum malaria in epidemic-prone regions of Ethiopia I. Patterns of lagged weather effects reflect biological mechanisms. Malar J 3(1):41 
Wang D, Hu B, Hu C, Zhu F, Liu X, Zhang J, et al. (2020a). Clinical characteristics of 138 hospitalized patients with 2019 novel coronavirus-infected pneumonia in Wuhan, China. JAMA

Tellier R (2009) Aerosol transmission of influenza A virus: a review of new studies. J R Soc Interface 6(suppl 6):S783-S790

Wang J, Tang K, Feng K, Lv W (2020b). High temperature and high humidity reduce the transmission of COVID-19. Available at SSRN 3551767

Wang M, Jiang A, Gong L, Luo L, Guo W, Li C, Chen Y (2020c). Temperature significant change COVID-19 transmission in 429 cities. MedRxiv

Ward MP, Xiao S, Zhang Z (2020) The role of climate during the COVID-19 epidemic in New South Wales, Australia. Transbound Emerg Dis 67(6):2313-2317

Wu W, Xiao Y, Li G, Zeng W, Lin H, Rutherford S, Ma W (2013) Temperature-mortality relationship in four subtropical Chinese cities: a time-series study using a distributed lag non-linear model. Sci Total Environ 449:355-362

Wu Y, Jing W, Liu J, Ma Q, Yuan J, Wang Y, du M, Liu M (2020) Effects of temperature and humidity on the daily new cases and new deaths of COVID-19 in 166 countries. Sci Total Environ 729: 139051

Xie J, Zhu Y (2020) Association between ambient temperature and COVID-19 infection in 122 cities from China. Sci Total Environ 724:138201

Yang J, Ou CQ, Ding Y, Zhou YX, Chen PY (2012) Daily temperature and mortality: a study of distributed lag non-linear effect and effect modification in Guangzhou. Environ Health 11(1):63

Zhu N, Zhang D, Wang W, Li X, Yang B, Song J, Zhao X, Huang B, Shi W, Lu R, Niu P, Zhan F, Ma X, Wang D, Xu W, Wu G, Gao DF, Tan W (2020) A novel coronavirus from patients with pneumonia in China, 2019. N Eng J Med 382:727-733

Zoran MA, Savastru RS, Savastru DM, Tautan MN (2020) Assessing the relationship between surface levels of $\mathrm{PM}_{2.5}$ and $\mathrm{PM}_{10}$ particulate matter impact on COVID-19 in Milan, Italy. Sci Total Environ 738: 139825

Publisher's note Springer Nature remains neutral with regard to jurisdictional claims in published maps and institutional affiliations. 